\title{
Leitura e compreensão leitora - estratégias, práticas e avaliação da leitura em contexto escolar
}

\author{
Ângela Balça ${ }^{1}$ \\ Renata Junqueira de Souza ${ }^{2}$
}

Ana Cristina Guerreiro ${ }^{3}$

\section{Resumo}

$\mathrm{Na}$ presente investigação, aspirou-se contribuir para o entendimento do desempenho dos alunos portugueses de $9^{\circ}$ ano, no Teste Intermédio de Língua Portuguesa 2010, no domínio da compreensão na leitura. Os objetivos do estudo eram conhecer as representações dos alunos sobre a leitura; saber se estes utilizavam estratégias de leitura para atingir uma melhor compreensão; perceber se os alunos consideravam a disciplina de Língua Portuguesa como promotora de aprendizagens transversais; avaliar o manual escolar, em relação à compreensão na leitura; $\mathrm{e}$ compreender a política da escola em relação à leitura. O estudo de caso desenvolveu-se por meio de inquérito por questionário a alunos de $9^{\circ}$ ano e de análise documental. Os resultados propenderam para uma valorização moderada da leitura por parte dos alunos, assim como para incipientes práticas de ensino da compreensão na leitura, o que, provavelmente, se refletiu nos resultados pouco satisfatórios daqueles alunos no referido Teste.

Palavras-Chave: leitura; compreensão leitora; estratégias de leitura; avaliação da leitura.

\footnotetext{
1 Doutora em Ciências da Educação pela Universidade de Évora (Portugal) e Professora do Departamento de Pedagogia e Educação da Universidade de Évora (Portugal). angela.balca@mail.evora.net 2 Doutora em Letras pela Universidade Estadual Paulista Júlio de Mesquita Filho. Professora do Programa de Pós-graduação em Educação da UNESP/ Presidente Prudente-SP. recellij@gmail.com 3 Mestre em Educação pela Universidade de Évora.
} 


\title{
Reading and reading comprehension - strategies, practices and assessment in school
}

\begin{abstract}
The present investigation tried to contribute to the understanding of 9th grade Portuguese students performance in the domain of reading comprehension, being evident at the Intermediate Test of Portuguese 2010. The study objectives were to know the representations of students about reading; to know if the students used reading strategies to achieve a better reading comprehension; understand if the students considered the subject of Portuguese Language as a promoter of cross learning; evaluate the textbook in relation to reading comprehension; and understand the school's policy in relation to reading. The case study has developed itself through a survey to the students, besides analyzing the documents. The results seem to point to a moderate valorization of reading on behalf of the students, as well as for the incipient practices of teaching reading comprehension, what possibly has reflected in the less satisfactory results of students in Test.
\end{abstract}

Keywords: reading; reading comprehension; reading strategies; reading assessment.

\section{Introdução}

Apesar de algum frenesi na sociedade atual, sobretudo na comunicação social, face aos resultados dos alunos portugueses nos Exames Nacionais, visível na publicação de rankings das escolas, qualquer profissional da educação sabe que, no desenvolvimento cognitivo do aluno, é mais importante o processo de aprendizagem do que o produto, para que ocorra um salto qualitativo em direção ao sucesso escolar e, consequentemente, uma integração socioprofissional na comunidade, permitindo igualmente uma aprendizagem ao longo da vida. De acordo com Pacheco (2011), a sociedade do conhecimento estimulou uma mudança paradigmática, que se configurou numa ressignificação do 
currículo e de formas diversas de organização curricular. Nesse novo paradigma, o ensino da língua portuguesa continua a desempenhar um papel fulcral, contribuindo sobremaneira para o domínio de competências cognitivas, linguísticas e culturais, que concorrem para o fomento/desempenho cada vez mais elevado das competências de letramento dos alunos.

Perante essa consciencialização e o cenário desfavorável dos resultados dos alunos portugueses de quinze anos, sobretudo dos que ainda se encontram a frequentar o ensino básico, em letramento em leitura, em particular nos testes do Programme for International Student Assessment (PISA), cabe-nos perguntar como lê um aluno de $9^{\circ}$ ano? Que estratégias de leitura mobiliza para retirar informações de um texto, com o objetivo de o estudar, ou até ler por prazer? Pode estabelecer-se uma relação entre a utilização de estratégias de leitura e desempenho escolar? Qual o lugar da Língua Portuguesa no currículo do ensino básico? Qual a pertinência, a legitimidade e a possibilidade da sua transversalidade?

Valerá a pena esclarecer que o sistema de ensino português é composto, de acordo com a Lei de Bases do Sistema Educativo, de 1986, pela educação pré-escolar, pelo ensino básico, que se divide em $1^{\circ}, 2^{\circ}$ e $3^{\circ}$ ciclos, e pelo ensino secundário. Os alunos do $9^{\circ}$ ano encontram-se no último ano do $3^{\circ}$ ciclo do ensino básico e têm, aproximadamente, quinze anos.

\section{Leitura: estratégias, práticas, avaliação}

A disciplina de Língua Portuguesa é um espaço em que a língua materna é não só objeto de estudo, como também instrumento de comunicação, extravasa os seus limites e torna-se, segundo Castro (1995), objeto curricular transversal, uma vez que qualquer transmissão ou aquisição de conhecimento, desenvolvimento de atitudes ou capacidades são feitos por meio da língua materna, sobretudo na sua vertente escrita.

Dessa forma, a todas as áreas curriculares (disciplinares e não disciplinares) são exigidas práticas que permitam o aperfeiçoamento progressivo de capacidades discursivas do aluno. Tal fato não quer dizer que todos os professores sejam professores de português (uma falácia 
comum, segundo Castro (1995)), mas sim que "as aulas são sempre contextos de aquisição linguística" (CASTRO, 1995, p. 100), que validam determinados usos padronizados da língua, apoiados, na maior parte das vezes, em material escrito. Considerando que todas as disciplinas são espaços de ensino e de aprendizagem da língua materna, que "toda a experiência escolar é, em larga medida, uma experiência linguística" (VALADARES, 2003, p. 13), então temos de assumir as tarefas de promoção da leitura, da escrita e da oralidade como projeto conjunto, transversal ao currículo escolar.

A importância matricial da língua portuguesa na formação do aluno e o concomitante caráter transdisciplinar da língua materna estão reconhecidos, de forma explícita, em vários documentos legais, destacando-se a Lei n. 46/1986, de 14 de outubro (Lei de Bases do Sistema Educativo); o Despacho Normativo n. 1/2005, de 5 de janeiro, que revogou o Despacho Normativo n. 30/2001, de 19 de julho, referente à avaliação das aprendizagens no ensino básico; o Plano Nacional de Leitura, lançado em junho de 2006; o Programa Nacional de Ensino do Português, iniciado no ano letivo de 2006/2007; e o Programa de Português do Ensino Básico (REIS, 2009), documento em que se reconhece a aprendizagem da língua materna como componente essencial da formação escolar, e se aponta para a necessidade de uma abordagem transdisciplinar. Constata-se que nos documentos programáticos o ensino da leitura se orienta oficialmente no sentido de criar um leitor ativo, autônomo, criativo e crítico. Reconhece-se, igualmente, a importância da leitura como um meio de acesso ao conhecimento e de aprendizagem, sempre que mobiliza competências de compreensão inferencial.

Apesar do enfoque numa perspetiva crítica e ativa por parte do leitor, a operacionalização dessas orientações tem suscitado algum defasamento entre os pressupostos dos textos programáticos e a realidade. Chamamos a atenção para o panorama desvantajoso dos alunos de quinze anos, sobretudo dos que ainda se encontravam frequentando o ensino básico, em letramento em leitura, nomeadamente na avaliação do PISA nos ciclos 2000 (com o desempenho de 470 - nível 2), 2003 (com o desempenho de 478 - nível 2) e 2006 (com o desempenho de 472 - nível 2), com resultados 
inferiores à média da OCDE (ME/GAVE, 2001; RAMALHO, 2004; FERREIRA, 2007), atingindo-se, em 2009, pela primeira vez desde o início do programa, pontuações situadas na média dos desempenhos dos países participantes, no domínio do letramento, com o desempenho de 489 nível 3. Registrou-se ainda, por um lado, a diminuição da percentagem de alunos com desempenhos de nível 1 e inferior e, por outro lado, o aumento da percentagem de alunos com desempenhos de nível 3, 4, 5 e 6 (SERRÃO; FERREIRA; SOUSA, 2010). A escala de leitura utilizada na avaliação PISA encontra-se dividida em cinco níveis de conhecimento e de competências, tendo em consideração os processos de recuperação de informação, interpretação de texto, reflexão e avaliação, além do formato do texto, de forma a descrever o que os estudantes conseguem fazer, por meio da associação das tarefas a níveis de dificuldade.

Tendo em conta as pontuações médias obtidas pelos estudantes portugueses, constatamos que, nos três primeiros ciclos, em termos médios, os alunos conseguiam realizar apenas tarefas básicas de leitura, envolvendo a localização simples de informação, inferências de nível inferior, compreensão do significado de partes bem definidas do texto e o estabelecimento de ligações entre o texto e conhecimentos exteriores ao mesmo. Em 2009, registra-se uma evolução, situando-se os alunos portugueses, em termos médios, no nível imediatamente superior. Assim, o seu perfil já aponta para a capacidade de realizar tarefas com complexidade moderada, que envolvem a localização de vários segmentos de informação, de forma a comparar, contrastar ou categorizar; a compreensão exaustiva do texto e sua relação com o conhecimento familiar e cotidiano.

Perante esses resultados modestos, assumidos politicamente como informantes nacionais, faz todo o sentido promover reflexões sobre os desempenhos dos alunos portugueses e formas de os melhorar. De acordo com Afonso e Costa (2009), os decisores políticos dão especial relevância aos estudos internacionais, aos indicadores de desempenho e às boas práticas, num quadro de crescente complexidade das ações do Estado e da presença de múltiplos atores na construção de políticas, nesse caso, educativas. Aliás, 
os estudos internacionais podem pressionar os mais diversos agentes do sistema educativo no sentido de alterarem as suas práticas e procedimentos, podem ajudar os governos a justificar ou a fundamentar mudanças nos currículos, nos sistemas de formação de professores, nos sistemas de alocação de recursos às escolas ou nos sistemas de gestão e administração escolar. Mas podem também constituir uma pressão sobre os próprios governos para que adequem e alterem as suas políticas educativas. (FERNANDES, 2008,p. 125).

A dificuldade dos alunos, no que ao conhecimento da língua materna diz respeito, nomeadamente no desenvolvimento da compreensão leitora, tem sido também comprovada por meio das provas de avaliação externa, pelos resultados medianos no Exame Nacional de Língua Portuguesa de $3^{\circ}$ ciclo (com uma média de 56\% quer em 2009, quer em 2010 (Júri Nacional de Exames, 2010)) e no Teste Intermédio de Língua Portuguesa, em 2010, com uma média nacional de 52\% (GAVE, 2010).

O Teste Intermédio de Língua Portuguesa é um instrumento de avaliação externa, disponibilizado pelo Ministério da Educação português, que é aplicado sensivelmente a meio do ano letivo e cujo objetivo é possibilitar a aferição de conhecimentos dos alunos, tendo como referência padrões de âmbito nacional.

A importância destes instrumentos de avaliação reside no fato de, por meio das operações de leitura solicitadas, analisarmos a concepção de leitura e o perfil de leitor considerados de referência a nível nacional. No estudo realizado por Alves (2007), conclui-se que "os princípios que presidem à elaboração das provas oficiais são coerentes com o perfil de leitor e leitura contidos nos textos programáticos" (ALVES, 2007, p. 129), na medida em que neles se perspectiva o trabalho do leitor como sendo fundamentalmente "uma tarefa de reconstrução dos significados do texto e não uma atividade caracterizada pela transmissão de conceitos, regras, factos linguísticos e literários, pela imitação de modelos, etc., conforme é encarada frequentemente nas práticas pedagógicas" (ALVES, 2007, p. 129). Partindo do pressuposto de que ler é mais do que descodificar a mensagem escrita, já que implica extrair significados do que é lido, ou seja, ler é compreender (SIM-SIM, 2007; COLOMER; CAMPS, 2008; RIBEIRO et al., 2010), procuramos entender o papel ativo do leitor (o 
aluno) e a função motivadora dos textos (presentes no manual escolar), num contexto significativo de aprendizagem (a sala de aula). Aí, a ação do professor desempenha um papel fundamental, de forma a "inibir as consequências negativas de fatores de índole social, pessoal e política que, desde há várias décadas se sabe, aparecem associados ao insucesso em compreensão leitora" (TRINDADE, 2009, p. 292). De fato, as atividades propostas aos alunos, a focalização da instrução e a qualidade e adequação dos textos fazem parte da esfera de ação do professor, contribuindo ou não para a criação de ambientes motivadores de leitura e para a anulação do círculo vicioso constituído pela relação entre situação familiar, econômica e socialmente desfavorecida, pouco prazer na leitura e baixos níveis literácitos (COUTINHO; AZEVEDO, 2007).

De acordo com OECD (2009), investigação recente reconhece a motivação, a atitude e o comportamento ativo como elementos essenciais relacionados com o desempenho na leitura, para além do desenvolvimento de conhecimentos. Giasson (2000), tendo em conta os trabalhos de Irwin, acrescenta ainda o recurso a habilidades necessárias para compreender uma informação contida numa frase, efetuar ligações entre as frases, apreender o sentido global do texto, estabelecer inferências ou gerir o processo de compreensão. Araújo (2007) salienta igualmente que "o treino em estratégias cognitivas e metacognitivas pode levar os alunos a melhorar consideravelmente a compreensão inferencial" (ARAÚJO, 2007, p. 11), sendo que esse treino passa por "levantar questões durante a leitura, prever acontecimentos, clarificar sentidos ambíguos e resumir pequenas parcelas de texto" (ARAÚJO, 2007, p. 11), além da reflexão sobre o tipo de compreensão a que corresponde as perguntas de um texto.

Reconhecendo a importância do treino da compreensão inferencial no desenvolvimento da competência de leitura, cabe-nos refletir sobre a situação dos alunos que terminam o $3^{\circ}$ ciclo do ensino básico e a forma como o currículo, os manuais e os professores exercitam esse tipo de compreensão. Segundo Araújo (2007), em Portugal, privilegia-se a compreensão literal em detrimento da compreensão inferencial quer nas orientações curriculares quer nos manuais escolares. Considerando que, segundo Sim-Sim (2007), o ensino explícito da compreensão da 
leitura não tem sido uma prática docente comum, limitada, muitas vezes, ao ensino da decifração, tem sido deixado aos alunos "o papel de adivinhar o que deveriam fazer para se tornarem leitores de sucesso" (SIM-SIM, 2007, p. 24). Essa situação tem reflexos nos resultados dos estudantes em provas nacionais e internacionais, pois, de acordo com Sim-Sim (2007), muitos alunos têm dificuldade em descobrir a forma de abordar um texto e, "perante textos de complexidade variada, não são capazes de colher a informação neles contida e com ela construir o conhecimento de que precisam para estudar, trabalhar e até mesmo fruir o prazer da leitura recreativa" (SIM-SIM, 2007, p. 24). Daí a urgência de clarificar os procedimentos e estratégias ativadas no ato de ler, assim como o comportamento do leitor enquanto exegeta que, servindo-se do texto, das suas vivências e da sua intenção de leitura, atinge uma fruição plena do texto. É importante frisar que essa centralidade na formação de um leitor crítico, competente e reflexivo está na base do Programa de Leitura Fundamentado na Literatura, desenvolvido por Hallie Kay Yopp e Ruth Helen Yopp. Esse Programa desenvolve-se com atividades de pré-leitura, atividades durante a leitura e atividades após a leitura, com os objetivos de, num primeiro momento, segundo Pontes e Barros (2007), "ativar e construir a competência enciclopédica do aluno [...], encorajando-o a expressar as suas ideias e a partilhar as suas experiências" (PONTES; BARROS, 2007, p. 71), e despertar a curiosidade dos alunos; num segundo momento, visa-se preparar o aluno para usar estratégias de compreensão, concentrá-lo na estrutura do texto, focar a sua atenção na riqueza expressiva da linguagem, facilitar a compreensão sobre aspetos particulares do texto, de forma a que o aluno experimente "uma relação afetiva com o texto" (PONTES; BARROS, 2007, p. 72); num terceiro momento, pretende-se promover a reflexão sobre o texto, oral ou escrita, identificando o que foi ou não significativo, face às expectativas criadas inicialmente.

Essas atividades constituem, sobretudo, alternativas aos questionários unívocos presentes nos manuais escolares. Alves (2007) salienta, para além das questões relativas à formação teórica de cada docente, o lugar de destaque que o manual escolar ocupa, infelizmente, nas práticas 
pedagógicas em torno da leitura, uma vez que, muitas vezes, consistem na leitura de textos, formulação de perguntas de avaliação e exercícios sobre o funcionamento da língua ou sobre aspetos formais do texto. Por essas razões, o manual escolar parece condicionar bastante os seus leitores, uma vez que restringe as atividades e valida determinadas práticas. Nesse sentido, o ensino da compreensão da leitura com base no manual escolar pode ser redutor (pela presença massiva de perguntas sobre o produto, que avaliam a aquisição de conhecimentos) e não ensina verdadeiramente o aluno a ler o texto escrito (pela ausência de perguntas sobre o processo, que promovem a explicitação do raciocínio e das estratégias utilizadas), daí ser necessário adotar outros modelos de ensino que ensinem efetivamente o aluno a ler, tornando-o um elemento mais ativo e, por isso, um leitor mais capaz e autônomo.

\section{O estudo, análise e discussão dos resultados}

Numa primeira parte, o estudo centrou-se nas representações de alunos de $9^{\circ}$ ano de escolaridade de uma escola básica do distrito de Évora, sobre a leitura em geral e as estratégias utilizadas antes, durante e após a leitura de um texto, pretendendo aferir em que medida as práticas pedagógicas apreendidas e utilizadas pelos alunos se relacionavam com o seu desempenho numa prova de avaliação externa, o Teste Intermédio de Língua Portuguesa, aplicado no ano letivo de 2009/2010.

Esse instrumento, do qual selecionamos os grupos e itens diretamente relacionados com a leitura, foi utilizado enquanto Teste de Compreensão de Leitura (TCL), por um lado, pelo seu teor eminentemente formativo, pois permitia aferir o desempenho dos alunos por referência a padrões de âmbito nacional e dava azo a delinear estratégias de melhoria, e por outro lado, segundo Sim-Sim e Viana (2007), os poucos instrumentos ao serviço da avaliação da leitura da população escolar portuguesa ou se encontram ainda em fase de elaboração ou não apresentam as características básicas para poderem vir a ser utilizados de forma padronizada.

Partindo dos normativos legais sobre a reorganização curricular do ensino básico (Decreto-Lei n. 6/2001, de 18 de janeiro) e das 
potencialidades da gestão flexível do currículo e incidindo, por outro lado, nas competências gerais de caráter transversal, nas quais a compreensão em leitura se insere, a segunda parte da investigação visou verificar a concretização das medidas de política educativa ao nível dos documentos de gestão pedagógica do Agrupamento de Escolas em causa, nomeadamente o Projeto Educativo, o Projeto Curricular de Escola e os Projetos Curriculares de Turma. Outro instrumento que mereceu a nossa atenção, pela primazia nas práticas de leitura em sala de aula, foi o manual escolar de Língua Portuguesa adotado na escola para o $9^{\circ}$ ano de escolaridade. Pretendíamos averiguar se esses documentos refletiam e promoviam uma valorização da leitura como domínio de formação transdisciplinar, atendendo à realidade e necessidades dos alunos e da escola.

De acordo com a problemática delineada, constituiu-se como objetivo geral deste estudo tentar compreender a forma como lia um aluno no final do $3^{\circ}$ ciclo do ensino básico. Pretendeu-se, ainda, explorar contextos de leitura significativos para o aluno (expressos nos documentos orientadores da escola, apreendidos e atualizados diariamente pelos alunos nas várias disciplinas) e relacioná-los com a formação de um leitor competente, avaliada, nesse caso, pelo Teste de Compreensão da Leitura e com os resultados escolares no conjunto das várias disciplinas.

Uma vez que se tinha a intenção de analisar e promover a operacionalização da transversalidade da Língua Portuguesa ao nível da compreensão em leitura numa determinada escola, mediante atores definidos para o efeito, a estratégia de estudo de caso pareceu-nos a mais ajustada, pois permitiu aprofundar o conhecimento de um aspecto da realidade. Essa estratégia possibilitou uma compreensão em profundidade, se bem que não generalizável, dos vários fatores que contribuíram para o desenvolvimento da competência leitora num determinado contexto educativo.

Os procedimentos de recolha e análise de dados estiveram, necessariamente, adequados à natureza mista (qualitativa e quantitativa) desses dados. Apesar do enfoque numa dimensão quantitativa, recorrendo-se a técnicas de análise estatística adequadas, no caso dos 
itens incluídos no Questionário ao Aluno e relacionados com o Teste de Compreensão da Leitura, na interpretação dos dados foi imprescindível o contributo de métodos qualitativos. Recorreu-se ainda a procedimentos de análise documental, quando da leitura dos documentos de gestão pedagógica da escola e do manual escolar.

A principal técnica de recolha de dados foi o inquérito por questionário. A triangulação dos dados foi conseguida a partir de um ponto de vista externo, dada pelos resultados do Teste Intermédio de Língua Portuguesa; concentrou se num ponto de vista individual, o Questionário preenchido por cada aluno de $9^{\circ}$ ano; divergiu para uma perspectiva de grupo-ano, analisando-se o manual escolar de Língua Portuguesa, adotado para esse ano de escolaridade, e os projetos curriculares das turmas envolvidas nesta investigação; finalmente, convergiu para a cultura de escola, expressa no Projeto Educativo e no Projeto Curricular de Escola.

Em seguida, apresentamos os principais resultados do estudo bem como a sua análise e discussão. Os 54 alunos participantes no nosso estudo obtiveram no TCL uma média de $61,4 \%$, com um desvio padrão de 17,2 . Quanto à taxa de sucesso, verificamos uma maioria $(n=33)$ de classificações iguais ou superiores a 50\% (positivas), embora seja relevante o número $(n=21)$ de classificações inferiores a $50 \%$ (negativas). Esses valores apontam para desempenhos moderadamente satisfatórios no domínio da leitura.

Procuramos, em primeiro lugar, interpretar esses dados em função do gênero, da idade e do contexto cultural e socioeconômico. Os resultados apontaram para a inexistência de diferenças relevantes entre os alunos e alunas no domínio da compreensão leitora, contrariamente ao demonstrado noutras investigações. Relativamente à frequência do ano de escolaridade equivalente à idade, ou seja, a um percurso escolar sem retenções, pudemos constatar uma associação entre o número de retenções e o desempenho dos alunos no referido teste. Confrontando as habilitações dos pais com os resultados dos alunos no TCL, não apuramos diferenças marcantes, por oposição à investigação de outros autores. Quanto ao contexto socioeconômico, averiguamos que, 
tendencialmente, os alunos com melhores condições econômicas tiveram, em termos médios, melhores resultados, não só no TCL como também na disciplina de Língua Portuguesa e na globalidade das disciplinas do ano de escolaridade.

Posteriormente, indagamos quais as representações dos alunos acerca da leitura, pois elas poderiam contribuir para o entendimento dos resultados pouco satisfatórios dos alunos no teste de compreensão leitora. A partir das respostas dadas, concluímos que as atividades de leitura, em termos médios, mereceram uma concordância moderada por parte dos alunos, não tendo sido tendencialmente algo que os alunos realizassem por prazer ou que gostassem de partilhar com amigos. Essa constatação conduziu a uma certa preocupação, uma vez que, segundo alguns autores como Coutinho e Azevedo (2007), os jovens que não manifestam prazer na leitura têm mais dificuldade em compreender e utilizar a informação escrita, sendo, por conseguinte, leitores menos competentes. Por outro lado, quando confrontados com as suas atitudes perante atividades de leitura com o objetivo de estudo, comuns a todas as disciplinas do currículo, os alunos tenderam a valorizar mais estratégias de controle da compreensão (por exemplo, verificação de que aprendeu o que era mais importante) do que de elaboração (por exemplo, estabelecimento de relações entre temas abordados em várias disciplinas ou a mobilização de conhecimentos prévios).

Considerando que o domínio de estratégias de leitura é essencial para que os alunos se tornem leitores competentes, a nossa terceira questão de investigação foi dirigida no sentido de saber se os alunos utilizavam, ou não, estratégias de leitura a fim de atingir uma melhor compreensão. Estabelecemos três situações/momentos: antes, durante e após a leitura de um texto, de acordo com a investigação mais recente no tema da compreensão em leitura.

Pudemos constatar que os alunos tendiam novamente a manifestar uma apetência moderada para a mobilização de conhecimentos prévios, o que denunciava uma prática pouco expressiva por parte dos professores. Acrescente-se que os dados recolhidos pela análise documental ao manual escolar de Língua Portuguesa apontaram, 
igualmente, para uma fraca ativação de estratégias de pré-leitura, o que não favorece, previsivelmente, o envolvimento do aluno com os textos, com o consequente desinteresse pela leitura. Relativamente às estratégias ativadas durante a leitura dos textos, os resultados indiciaram uma frequência reduzida de ações como sublinhar informação relevante, tomar notas à margem ou sintetizar partes do texto; também foi expressa uma tendência para alguma dificuldade em fazer inferências e deduções. Confrontando esses dados com a análise efetuada aos questionários presentes no manual escolar de Língua Portuguesa, verificamos que aqueles não apelavam para a monitorização do processo de compreensão, durante a leitura dos textos, com consequências nefastas para todas as áreas do saber. No que concerne às estratégias de pós-leitura, os alunos assumiram que verificavam a compreensão do sentido global do texto, conseguiam dizer o que aprenderam com o texto e reliam partes do texto para perceber melhor; contudo, a partilha de leituras não mostrou ser do agrado dos alunos. Os estudantes consideraram úteis, na generalidade, as estratégias de leitura apresentadas para compreender e reter informação.

A quarta questão da investigação dizia especificamente respeito à avaliação da compreensão na leitura no manual escolar de Língua Portuguesa. Adotado em 2004, editado pela Areal Editores, com coordenação de Artur Veríssimo, Ser em Português 9 é um manual desatualizado: os textos são, majoritariamente, excertos de obras literárias, há um número muito reduzido de textos da comunicação social e nenhum texto de outras áreas do saber; os questionários de verificação da compreensão dos textos são extensos e com uma tipologia de questões pouco variada, baseada, na sua grande maioria, em perguntas de resposta construída fechada ou de resposta curta, destacando-se a ausência de questões de escolha múltipla, tão frequentes em provas de avaliação externa, nacionais ou internacionais, ou mesmo em baterias de testes de avaliação da compreensão leitora. Relativamente às estratégias de leitura mobilizadas nos questionários de interpretação dos textos, elas são centradas, de forma quase exclusiva, em momentos após a leitura, tendo o objetivo de verificar ou aprofundar linhas de leitura propostas pelos autores do manual. A instância leitor, com um comportamento ativo de 
descoberta e construção de sentidos, após um momento de motivação, anula-se para ceder o lugar a uma leitura unívoca, contrariando as orientações programáticas. No Programa de Língua Portuguesa, salientase que "ler não pode, pois, restringir-se à prática exaustiva da análise quer de excertos quer mesmo de obras completas. O prazer de ler, a afirmação da identidade e o alargamento das experiências resultam das projeções múltiplas do leitor nos universos textuais" (REIS, 2009, p. 19).

A quinta questão de investigação prendia-se com a opinião dos alunos sobre a disciplina de Língua Portuguesa como promotora de aprendizagens conducentes ao desenvolvimento de competências essenciais em todas as disciplinas. Foi com agrado que verificamos que, em termos médios, a leitura era considerada importante para o desenvolvimento de outras competências da língua, com reflexos na aprendizagem noutras disciplinas e para além do percurso escolar. Todavia, essa representação positiva da leitura, envolvendo conteúdos de outras áreas do saber, não encontrou expressão no manual escolar de Língua Portuguesa para o $9^{\circ}$ ano, em que há um predomínio de excertos de obras literárias, aconselhadas pelo Programa de Língua Portuguesa de há mais de vinte anos atrás (1991).

Por fim, a sexta questão de investigação incidia nos documentos de gestão pedagógica da escola (Projeto Educativo, Projeto Curricular de Escola e Projetos Curriculares de Turma), como orientadores, ou não, de uma política de escola direcionada para a melhoria da competência leitora dos seus alunos, numa perspectiva transversal. Constatamos que as atividades de leitura eram relegadas, no Projeto Educativo, para a biblioteca escolar; que o domínio da língua materna não era considerado como uma área prioritária de intervenção no Projeto Curricular de Escola, apesar de constar nos critérios gerais de avaliação dos alunos, como aprendizagem e competência de caráter transversal; que os Conselhos de Turma eram pouco permeáveis a um trabalho sistemático, consistente e articulado sobre a Língua Portuguesa, em geral, e ao desenvolvimento de competências associadas à compreensão na leitura, de forma específica, embora tenham sido registradas dificuldades dos alunos neste domínio. 


\section{Conclusões}

Como pretendíamos conhecer a realidade dos alunos de uma escola básica do distrito de Évora, em termos da compreensão da leitura, delineamos um estudo que pretendeu explorar contextos de leitura significativos para os alunos de $9^{\circ}$ ano (expressos nos documentos orientadores da escola, apreendidos e atualizados diariamente pelos alunos nas várias disciplinas) e relacioná-los com a formação de um leitor competente, avaliada, nesse caso, pelo Teste de Compreensão da Leitura (Teste Intermédio de Língua Portuguesa 2010) e pelos resultados escolares. De fato, os resultados dos alunos, no Teste Intermédio de Língua Portuguesa 2010, nesta escola, foram pouco satisfatórios.

Além das variáveis de contexto (familiar, socioeconômico e cultural) que podiam explicar os desempenhos dos alunos, também os fatores intrínsecos à gestão pedagógica da escola, nomeadamente a pouca importância e o não entendimento do caráter transversal da língua portuguesa, tenderam certamente a contribuir para esses resultados.

Seguramente, outros aspetos, que emergiram do estudo, podem ajudar a explicar o desempenho dos alunos no mencionado Teste. Assim, os alunos valorizaram, de forma moderada, a leitura, porém essa competência foi considerada importante, por eles, como promotora de aprendizagens em todas as disciplinas. Esses alunos utilizaram, de modo reduzido, estratégias de leitura, que lhes permitiriam aceder mais facilmente à compreensão e, em consonância, assistimos a incipientes práticas de ensino explícito da compreensão da leitura, situação muito potenciada pela não adequação do manual escolar adotado pela escola.

Nesta investigação, orientaram-nos dois princípios: investigar para conhecer e conhecer para intervir (móbil deste "estudo de caso"). Consideramos que só conseguiríamos aplicar eficazmente estratégias de intervenção na realidade escolar em que nos inserimos, no sentido de melhorar os níveis de proficiência em leitura, depois de um conhecimento aprofundado dos vários "ângulos" do ensino e da aprendizagem dessa competência. 


\section{Referências}

AFONSO, N.; COSTA, E. A influência do Programme for International Student Assessment (PISA) na decisão política em Portugal: o caso das políticas educativas do XVII Governo Constitucional Português. Sísifo. Revista de Ciências da Educação, v. 10, p. 53-64, 2009. Disponível em: <http://sisifo.fpce.ul.pt/pdfs/Revista \%2010\%20PT\%20D4.pdf>. Acesso em: 06 abr. 2012.

ALVES, P. Conceções e práticas pedagógicas sobre a leitura - Uma análise de provas de avaliação. Dissertação de mestrado (não publicada). Universidade do Minho. Braga, 2007. [Disponível em https:/ / repositorium.sdum.uminho.pt/ handle/1822/7263, consultado em 31/03/2010]

ARAÚJO, L. A compreensão na leitura: investigação, avaliação e boas práticas. In: AZEVEDO, F. (Coord.). Formar leitores. Das teorias às práticas. Lisboa: Lidel, 2007. p. 9-18.

BRASIL. Ministério da Educação. Gabinete de Avaliação Educacional. Resultados do estudo internacional PISA 2000, 2001. Disponível em: <http://www.gave.min edu.pt/np3content/?newsId=33\&fileName= primeiro_relatorio_nacional.pdf>. Acesso em: 04 fev. 2011.

CASTRO, R. V. Todos os professores são professores de Português. Para a crítica de uma falácia comum. In: PACHECO, J.; ZABALZA M. (Orgs.). A avaliação dos alunos nos ensinos básico e secundário. Braga: Universidade do Minho, 1995. p. 97-102.

COLOMER, T.; CAMPS, A. Ensinar a ler, ensinar a compreender. Porto Alegre: Artmed, 2008.

COUTINHO, V.; AZEVEDO, F. A importância do ensino básico na criação de hábitos de leitura: o papel da escola. In: AZEVEDO F. 
(Coord.). Formar leitores. Das teorias às práticas. Lisboa: Lidel, 2007. p. 35-43.

FERNANDES, D. Avaliação das aprendizagens: desafios às teorias, práticas e políticas. Lisboa: Texto Editores, 2008.

FERREIRA, C. (Coord.). PISA 2006 - Competências científicas dos alunos portugueses. Lisboa: GAVE/ME, 2007. Disponível em: <http://www.gave.min edu.pt/np3content/?newsId=33\& fileName=relatoio_nacional_pisa_2006.pdf>. Acesso em: 16 abr. 2010.

GAVE. Projeto testes intermédios. Relatório 2010, 2010. Disponível em: <http:// www.gave.min-edu.pt/np3content/?newsId=24\&fileName= TI_2010_ReportNet.pdf>. Acesso em: 02 fev. 2011.

GIASSON, J. A compreensão na leitura. Porto: Edições Asa, 2000.

JÚRI NACIONAL DE EXAMES/EXAMES NACIONAIS/2010, 2010. Disponível em: <http:/ / sitio.dgidc.min-edu.pt/JNE/Documents/ Estat/2010/Resultados_EB_2010.pdf>. Acesso em: 02 fev. 2011.

OECD. PISA 2009 Assessment Framework - Key Competencies in Reading, Mathematics and Science, 2009. Disponível em: <http:/ / www.oecd. org/dataoecd/11/40/44455820.pdf>. Acesso em: 18 out. 2010.

OECD. Résultats du PISA 2009: synthèse, 2010. Disponível em: <http://www.pisa.oecd.org/ dataoecd/33/5/46624382.pdf>. Acesso em: 04 fev. 2011.

PACHECO, J. A. Currículo, aprendizagem e avaliação. Uma abordagem face à agenda globalizada. Revista Lusófona de Educação, Portugal, v. 17, p. 75-90, 2011. Disponível em: <http:// revistas. ulusofona.pt/index.php/rleducacao/article/view/2366/1866>. Acesso em: 06 abr. 2012. 
PONTES, V.; BARROS, L. Formar leitores críticos, competentes, reflexivos: o programa de leitura fundamentado na literatura. In: AZEVEDO F. (Coord.). Formar leitores. Das teorias às práticas. Lisboa: Lidel, 2007. p. 69-87.

RAMALHO, G. (Coord.). Resultados do estudo internacional PISA 2003, 2004. Disponível em: <http://www.gave.minedu.pt/np3content/?ne wsId=33\&fileName=relatorio_nacionna_pisa2003.pdf $>$. Acesso em: 04 fev 2011.

REIS, C. (Coord.). Programa de português do ensino básico. Lisboa: Ministério da Educação/ Direção-Geral de Inovação e Desenvolvimento Curricular, 2009.

RIBEIRO, I. et al. Compreensão da leitura: dos modelos teóricos ao ensino explícito: um programa de intervenção para o $2{ }^{\circ}$ ciclo do ensino básico. Coimbra: Almedina, 2010. Disponível em: <http:/ / repositorium.sdum.uminho.pt/handle/1822/11216>. Acesso em: 12 jan. 2011.

SERRÃO, A., FERREIRA, C.; SOUSA, H. PISA 2009 - competências dos alunos portugueses: síntese de resultados, 2010. Disponível em: <http://www.gave.min edu.pt/np3content/?newsId=346\&fileName =Sintese_Resultados_PISA2009.pdf $>$. Acesso em: 04 fev. 2011.

SIM-SIM, I. O ensino da leitura: a compreensão de textos.

Lisboa: Ministério da Educação/ Direção Geral de Inovação e Desenvolvimento Curricular, 2007.

SIM-SIM, I.; VIANA, F. Para a avaliação do desempenho de leitura. Lisboa: Ministério da Educação/ Gabinete de Estatística e Planeamento da Educação, 2007.

TRINDADE, M. O ensino e a aprendizagem da compreensão leitora: 
algumas notas sobre o que está por fazer em Portugal. In: BONITO, J. (Org.). Ensino, qualidade e formação de professores. Évora: Departamento de Pedagogia e Educação da Universidade de Évora, 2009. p. 291- 307.

VALADARES, L. Transversalidade da língua portuguesa. Porto: Edições Asa, 2003. 